\title{
Results-Based Organization Design for Technology Entrepreneurs
}

\author{
Chris McPhee
}

\author{
"Failure comes only when we forget our ideals") \\ and objectives and principles. \\ Jawaharlal Nehru (1889-1964) \\ 1st Prime Minister of India
}

\begin{abstract}
Faced with considerable uncertainty, entrepreneurs would benefit from clearly defined objectives, a plan to achieve these objectives (including a reasonable expectation that this plan will work), as well as a means to measure progress and make requisite course corrections. In this article, the author combines the benefits of results-based management with the benefits of organization design to describe a practical approach that technology entrepreneurs can use to design their organizations so that they deliver desired outcomes. This approach links insights from theory and practice, builds logical connections between entrepreneurial activities and desired outcomes, and measures progress toward those outcomes. This approach also provides a mechanism for entrepreneurs to make continual adjustments and improvements to their design and direction in response to data, customer and stakeholder feedback, and changes in their business environment.
\end{abstract}

\section{Introduction}

Technology entrepreneurs face many challenges when trying to turn ideas into profitable businesses. Aside from the challenge of creating products or services that customers will want to pay for, entrepreneurs also face the challenge of creating an organization that functions efficiently and delivers the outcomes that founders and investors desire. As an organization, a technology firm may grow organically in response to internal or external demands, but that does not necessarily mean it is finely tuned to achieve particular outcomes, assuming these outcomes have been defined. Even when organizations have well-defined objectives, there may not be a logical connection between the organization's structures, processes, and activities or any theoretical or practical understanding about the mechanisms by which the desired outcomes may be achieved. Organizations may be a result of happenstance as much as intention.

In this article, the author introduces an approach that can help technology entrepreneurs design and continually refine their organizations to increase the likelihood that they will deliver the desired immediate, intermediate, and ultimate outcomes. First, the author describes a cyclical organization design process that integrates lessons from theory and practice into the design of an organization. Next, a results-based management approach is described to show how it links activities to outcomes and provides a mechanism for measuring progress toward those outcomes. Next, the author combines these two approaches to create a new approach called "results-based organization design". Then, the article provides a hypothetical example of how this approach can be applied to the design of a technology startup. Finally, several implementation tips are provided and conclusions are offered.

\section{Organization Design}

Researchers in the field of organization design seek to better understand the functions and processes of organizations and how they can be improved. A design perspective implies that organizations can be deliberately constructed (or changed) through research and are not simply the subjects of passive observation or theoretic- 


\section{Results-Based Organization Design for Technology Entrepreneurs}

\section{Chris McPhee}

al models. In practice, organizations do not emerge fully formed from the ether, and while they may change in response to internal and external demands, their creators often engage in a some form of design process before and after their construction. What separates the practical activity of "designing organizations" from the research activity of "organization design" is that the latter is grounded in theory, which should improve the chances that the resulting organization will deliver the outcomes desired by its designer.

The importance of linking theory and practice in organization design was recognized by Georges Romme (tinyurl.com/8yyakyt) and colleagues, who developed a cyclical approach to designing and improving organizations based on a set of design principles. Design principles are sets of propositions that are grounded in theory and practice, that is, they draw upon lessons learned from both practical experience and from academic literature (Romme and Endenburg, 2006: tinyurl.com/6aowwdz; van Burg et al., 2008: tinyurl.com/3v3787c). Design principles inform subsequent design and implementation steps in the process originally proposed by Romme and Endenburg (2006), which they called "science-based organization design". The steps in this design process are:

1. Gather lessons from theory and practice. This step captures what is known about subjects relevant to the design task, including both practical experience and academic literature.

2. Formulate design principles. This step synthesizes the lessons from theory and practice into a set of propositions that provide a guiding light in the design process. Design principles are sufficiently general that they could be used by others faced with similar design challenges.

3. Formulate design rules. This step develops guidelines that are grounded in one or more design principles and are specific to the design context. Design rules are solution-oriented and make a logical connection between the focus of a given design rule and its expected outcome. A good design rule will "contain information on what to do, in which situations, to produce what effect and offer some understanding of why this happens" (Denyer et al., 2008; tinyurl.com/7xvkmh5).

4. Design the organization. This step applies the design rules into the development of a specification for the intended organization.
5. Implement the design. This step applies the design to the actual construction of the new organization.

6. Observing the new organization. This step assesses how well the organization works. Based on observations (and possibly experiments as well), new ideas for improving the design may be generated. These ideas should be used to alter any or all of the previous steps through a redesign process. Thus, these steps do not describe a linear process, but rather form a closed-loop feedback system through which continuous improvements can be made.

The organization design process described above includes three important elements: i) grounding in both theory and practice; ii) logical connections between design elements and desired outcomes; and iii) a mechanism for ongoing improvement to the design. However, this overall process does not include specific guidance on how to relate design elements to outcomes on different timescales. It also does not provide practical guidance on how the feedback loop should be closed (i.e., what data should be collected and how it should be used). In the section that follows, another approach is described; when combined with an organization design approach, it offers solutions that fill these two gaps.

\section{Results-Based Management}

Managers often face the challenge of connecting what their organization is doing "on the ground" today with the broad-scale outcomes they ultimately hope to achieve. In some cases, the desired outcomes may be vague, poorly articulated, or disconnected from the actual activities the organization undertakes; in other cases, the outcomes may be undefined or not shared by all stakeholders. Furthermore, the ultimate outcome desired by an organization may require long-term commitment, and it may be difficult to know whether immediate-term activities are producing results that will lead the organization efficiently toward those outcomes. An approach that is suited to such situations is "results-based management", which provides a set of working tools that allow managers to evaluate the performance of initiatives against defined outcomes.

Although results-based management can be applied in many different situations, it is common in the public sector and the non-profit/community sector. It is especially common in international development contexts, where long-term development objectives, such as improving 


\section{Results-Based Organization Design for Technology Entrepreneurs}

\section{Chris McPhee}

health in a particular region, are difficult to connect with the actual activities undertaken, such as providing health education services to individual communities within that region. As an example, the Canadian International Development Agency (CIDA; acdi-cida.gc.ca) has over 30 years of experience refining its results-based management approach, which it uses to manage its international development projects and investments. In this context, the approach improves decision making, transparency, and accountability (CIDA, 2008; tinyurl.com/3jy985q).

At the core of CIDA's approach is the logic model, which is a common feature of results-based management. The logic model is "a depiction of the causal or logical relationships between inputs, activities, outputs, and the outcomes of a given policy, program or investment" (CIDA, 2008; tinyurl.com/3jy985q). CIDA's descriptions of these components are summarized below:

1. Ultimate outcome: the long-term objective or the top-level, measureable change that the initiative is designed to effect. This component answers the question: "Why are we doing this?"

2. Intermediate outcomes: medium-term objectives that are expected to logically follow on from the achievement of the immediate outcomes. Intermediate outcomes are usually associated with changes in behaviour or practices, and they must be measurable.
3. Immediate outcomes: short-term objectives that are the direct result of the outputs of activities. Immediate outcomes are usually associated with increased awareness, skills, or access, and they must be measurable.

4. Outputs: the measurable products of activities.

5. Activities: the actual items of work undertaken to produce outputs.

6. Inputs: the financial, human, material, and information resources available to undertake activities. In CIDA's framework, including this component in the logic model is optional, although they obviously are still required to carry out the specified activities.

The format of the logic model is a table that lists the activities and outputs and the immediate, intermediate, and ultimate outcomes of an initiative (see Table 1). Cells near the top of the table may be merged with adjacent cells in the same row to indicate outcomes that are a product of multiple activities and outputs. Ideally, managers complete the logic model with input from stakeholders, which helps develop a complete and shared view of an initiative and its direction. The table may be completed from the top-down or the bottomup, depending on the situation, but the essential aspect is the logical connection between each related component, which creates a vertical chain of results.

Table 1. A logic model template*

\begin{tabular}{|l|l|l|l|l|}
\hline $\begin{array}{l}\text { Ultimate } \\
\text { Outcome }\end{array}$ & \multicolumn{2}{|l|}{} \\
\hline $\begin{array}{l}\text { Intermediate } \\
\text { Outcomes }\end{array}$ & \multicolumn{2}{|l|}{} \\
\hline $\begin{array}{l}\text { Immediate } \\
\text { Outcomes }\end{array}$ & & & & \\
\hline Outputs & & & & \\
\hline Activities & & & & \\
\hline
\end{tabular}

* For a more detailed template with instructions, see the CIDA website: tinyurl.com/3Innde6 


\section{Results-Based Organization Design for Technology Entrepreneurs}

\section{Chris McPhee}

The logic model is intrinsically linked to a second working tool: the performance measurement framework. The performance management framework uses the outcomes defined in the logic model to establish "a structured plan for the collection and analysis of performance information" (CIDA, 2008; tinyurl.com/3jy985q). This framework documents the major elements of the monitoring system, including performance indicators, baseline data, specified targets, and data sources. It also specifies whose responsibility it is to collect the data, how frequently it is to be collected, and how it will be collected (Table 2).

The logic model and performance management framework are used together to: i) define the logical relationships between what the initiative is meant to achieve and what activities are actually being done to work towards those outcomes and ii) monitor progress toward those outcomes, ensuring that the initiative will actu- ally deliver what it was designed to achieve. While commonly used to facilitate international development initiatives, the results-based management approach and templates are readily adapted to organization design efforts, as will be demonstrated in the sections that follow.

\section{A Combined Framework}

The organization design approach can be combined with the results-based management approach to yield a new approach for designing organizations: results-based organization design. This new approach maintains the benefits of organization design, particularly the practical and theoretical grounding of design principles and the closed-loop feedback loop, which provides a mechanism for ongoing improvement. By replacing design rules with a logic model that is guided by design principles, more explicit connections between design activities and their

Table 2. A performance management framework template*

\begin{tabular}{|l|l|l|l|l|l|l|l|}
\hline $\begin{array}{l}\text { Expected } \\
\text { Results }\end{array}$ & Indicators & $\begin{array}{l}\text { Baseline } \\
\text { Data }\end{array}$ & Targets & $\begin{array}{l}\text { Data } \\
\text { Sources }\end{array}$ & $\begin{array}{l}\text { Collection } \\
\text { Methods }\end{array}$ & Frequency & Responsibility \\
\hline \multirow{2}{*}{$\begin{array}{l}\text { Ultimate } \\
\text { Outcome }\end{array}$} & & & & & & & \\
\hline \multirow{3}{*}{$\begin{array}{l}\text { Intermediate } \\
\text { Outcomes }\end{array}$} & & & & & & & \\
\cline { 2 - 8 }
\end{tabular}




\section{Results-Based Organization Design for Technology Entrepreneurs}

\section{Chris McPhee}

outcomes across different timescales can be developed. Further, the performance management framework is intrinsically linked to the logic model and provides a practical solution to the challenge of closing the feedback loop and triggering changes "upstream" in the re-design process. Figure 1 illustrates the components of the results-based organization design approach. The shaded boxes highlight the components integrated from resultsbased management.

Results-based organization design follows a cycle of steps designed to answer the following questions:

1. Lessons from practice: What does our experience tell us?

\section{Lessons from theory: What does theory tell us?}

3. Design principles: What grounds our thinking? What tells us which solutions are likely to work?

4. Logic model: What is the link between what we intend to do and what we expect it will achieve, both right away and in the future?

5. Design solution: What do we intend to build?

6. Implementation: What did we actually build?

\section{Performance management framework: Is it working?}

8. Feedback loop: Where do we need to make changes?

The author has developed and applied this resultsbased organization design approach during the design and construction of the organization that produces and disseminates this journal, the Technology Innovation Management Review (TIM Review). However, this approach can be generalized to other design contexts. In the section that follows, the results-based organization design approach will be applied to a hypothetical example to illustrate how it can be used by technology entrepreneurs.

\section{An Example of Results-Based Organization Design}

In the March issue of the TIM Review, Stoyan Tanev described firms that are "born global", which means they are new ventures that "act to satisfy a global niche from day one" (Tanev, 2012; timreview.ca/article/532). Tanev described the characteristics of born-global firms, listed the conditions that are favourable for new technology companies considering early globalization, and under-
Figure 1. Results-based organization design

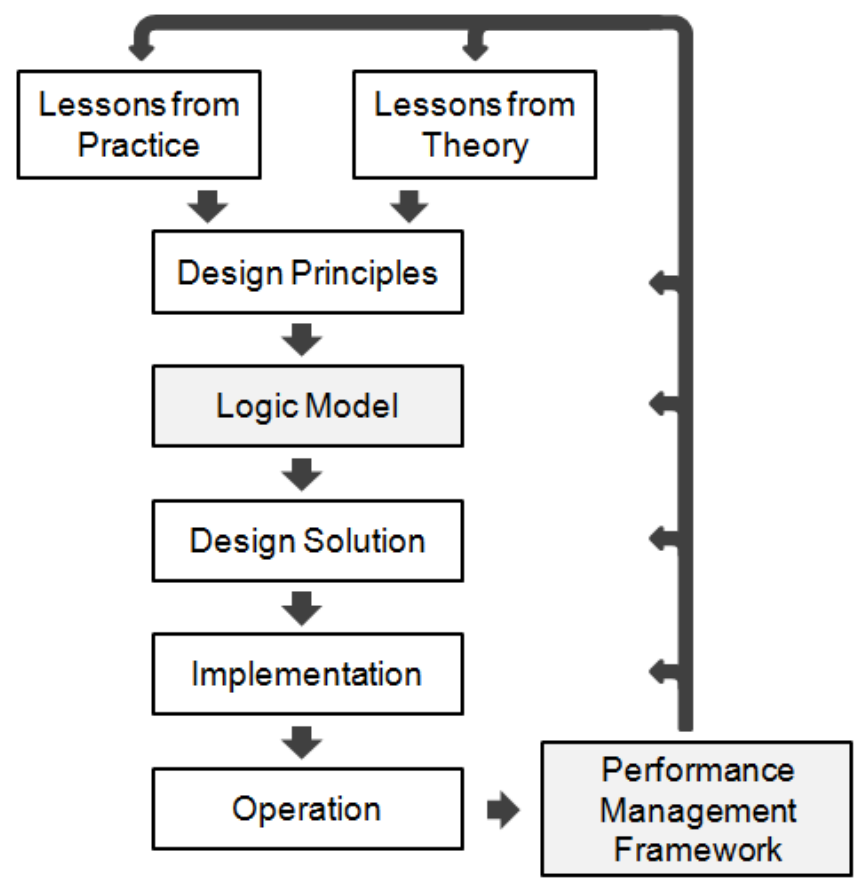

scored the importance of business ecosystems for the international performance of born-global firms. Tanev concluded his article with a call to identify the design principles that can be used to design technology startups that will be born global. In this section, the resultsbased organization design approach will be applied as a first step toward answering this call, but also to provide an example of how an entrepreneur might use this approach when designing a new technology venture. The example is not fully developed - it will just focus on a narrow slice of the approach - but it provides a starting point simply to illustrate how the approach can be applied to a technology entrepreneurship setting.

\section{Design principles}

As described above, design principles are synthesized from lessons from theory and practice. Tanev's (2012) article provides a starting point for research-based lessons, including the characteristics of born-global companies. For example, one characteristic is that managers of born-global companies "have a strong international outlook and international entrepreneurial orientation". The article also reports on a research study that examined the conditions for newly created technology firms considering early, rapid globalization; one of these conditions is the presence of key managers 


\section{Results-Based Organization Design for Technology Entrepreneurs}

\section{Chris McPhee}

with experience in international business (Kudina et al., 2008; tinyurl.com/83c2qdz). To develop a design principle, this lesson from research would be combined with knowledge from practical experience. A hypothetical lesson from practice might be, for instance, an observation that managers with international business experience with more than one country appear to be more successful in expanding into new geographic markets than specialists that have only conducted business with only one other country. The implied mechanism underlying this hypothetical observation might be that a breadth of experience allows managers to generalize solutions to internationalization challenges. Taken together, these lessons from research and practice might be synthesized into the following design principle: Ensure that the top management team has significant international business experience.

\section{Logic model}

All of the design principles (i.e., not just the one example above) would guide the development of the logic model. For example, an activity relating to recruitment might be guided by the design principle that relates to international business experience. In this case, the activity might be to recruit a management team, which would yield the output of the appointment of one or more managers, which in turn would contribute to the immediate outcome of a management team with broad international business experience. Based on the causal mechanisms identified in the research studies that underlie the design principles, there is a reasonable expectation that this immediate outcome can contribute to intermediate outcomes relating the success of a born-global company.

\section{Performance management framework}

In the performance management framework, each of the outputs and outcomes in the logic model will have measureable indicators. Following the narrow slice in the example above, an indicator for the activity to recruit a management team might relate to the average number of years of international business experience among candidates. Another indicator might relate to the breadth of international experience among candidates. If the data relating to these indicators fall below the predefined targets, action may be taken to reach a more appropriate pool of candidates. Similar indicators could be used for the output and outcome, thereby tracking the breadth and depth of experience among newly hired managers and across the entire management team. These metrics provides managers with an indication of the performance of the company against predefined targets and outcomes.
The hypothetical example developed in this section focused on a narrow slice - the full approach would include several more design principles and a full logic model and performance management framework. Nonetheless, this incomplete example hopefully shows how this approach does more than just measure progress; it provides a method for managers to act to improve the organization's performance over time. On the surface, it may seem obvious that a company interested in succeeded in international markets should seek staff with international experience, but this approach adds value by ensuring that such relationships are based on research and practice, not just assumptions about causal mechanisms. Further, this approach goes beyond "process and documentation"; it makes these principles an explicit part of the organization's culture. By making its key activities, outputs, and desired outcomes explicit and agreed among stakeholders, the company can proceed more efficiently toward the achievement of those outcomes.

\section{Benefits for Technology Entrepreneurs}

The results-based organization design approach can be applied to the design and creation of a new technology venture. This approach provides the following benefits for technology entrepreneurs:

1. A focus on the pathway to the desired outcomes for the organization. Depending on their motivation, it is easy for many entrepreneurs to envision an ultimate outcome for their organization; however, it can be difficult to plot the intermediate steps between their initial idea and achievement of the ultimate outcome. This approach defines outcomes across different timescales, with a logical connection between the outcomes and the activities undertaken. It can also expose any misguided faith the entrepreneur may have in an idea, market attribute, or technology feature if there is no reasonable connection to the desired outcomes; such roadblocks may helpfully encourage the entrepreneur to rethink their current approach.

2. Even within a small team, it can be difficult to build consensus around the organization's outcomes. The logic model provides a framework to develop a shared view of the organization's direction. This can be particularly helpful when the logic model is developed with input from stakeholders (e.g., co-founders, the wider team, investors, advisors, lead customers); it can also become a helpful way to summarize the essential features of an organization for others, such as potential investors. 


\section{Results-Based Organization Design for Technology Entrepreneurs}

\section{Chris McPhee}

3. It is natural to draw upon past experience and knowledge when making design decisions; however, an explicit process to capture and synthesize lessons from both theory and practice formalizes this process and forces the designer to justify why they think particular actions will have particular impacts. Gaps in thinking become readily apparent and stakeholders can work together to strengthen the "soft spots".

4. Technology entrepreneurs are often faced with new opportunities that threaten to shift the organization's focus. If results-based organization design has been implemented, it provides a means to evaluate whether new opportunities fit with the overall direction of the company. New opportunities may rejected if they do not fit into the agreed direction or are deemed a less efficient means of achieving the desired outcomes. Alternatively, the approach may help the entrepreneur weigh their options and decide to pursue the new opportunity.

5. It can be difficult for technology entrepreneurs to know whether their organization's various activities are having the desired effects. The results-based organization design approach provides a mechanism to capture and act upon performance data.

6. Technology entrepreneurs need to be able to quickly respond to changes in customer feedback, market demands, technological capabilities, and the business environment. The closed-feedback loop provides a mechanism to refine any aspect of the design on an ongoing basis.

7. The approach allows the company to develop intellectual property on how to grow the business. This intellectual property increases and becomes more valuable over time as the design is refined.

\section{Implementation Advice}

Despite the benefits of this approach, it does not guarantee success, particularly if careful consideration is not given to how it should be applied to a given situation. The following tips should help entrepreneurs apply this approach to the design of their own organizations:

1. Focus on a small number of important indicators in the performance management framework. If too many indicators are included or some of them are not actually measuring progress towards outcomes, then the effectiveness of the approach will diminish.
2. Resist the urge to capture everything. Focus on the elements that add incremental value. If including three extra design principles will not move the organization any closer to its ultimate outcome, then they are not worth adding.

3. Refine the approach over time. The goal is not to develop the perfect process on day one, nor is it to simply fill in the tables. Pay attention to the discussions around design principles, activities, and outcomes, as well as the logical connections between each of these elements. The learning and consensus-building that results from this process can be as valuable as the completed framework. As a cyclical approach, the design will naturally undergo iteration and refinement.

4. Apply the approach only to sufficiently stable situations. While logic models are expected to evolve over time, they are "implicitly linear" (Gamble, 2008; tinyurl.com/4xh6g39), which suggests they may not be suitable when innovation through rapid iteration and nonlinearity is an objective. This approach has broad applicability, but in the context of technology entrepreneurship, it may be more suitable for designing a technology startup (i.e., the organization) than for designing that startup's highly innovative product, which may involve rapid iteration on timescales that make this type of performance management inefficient.

5. Involve stakeholders in the process. In some cases, it may be most efficient to create drafts of the design principles and logic model and present them to stakeholders for feedback.

\section{Conclusion}

This article introduces results-based organization design, a practical approach that combines the benefits of organization design with the benefits of resultsbased management. It provides a means of integrating lessons from practice and theory into a design process that creates logical connections between an organization's activities and its desired outcomes while also providing a mechanism for ongoing refinement. While this approach is applicable to a variety of organization design challenges, this article makes a case that it may be particularly useful for technology entrepreneurs, who need to define clear outcomes and plan activities that can be expected to deliver those outcomes with little margin for error. 


\section{Results-Based Organization Design for Technology Entrepreneurs}

Chris McPhee

\section{Recommended Reading}

- "Construction Principles and Design Rules in the Case of Circular Design" by Georges Romme and Gerard Endenburg (2006; tinyurl.com/6aowwdz)

- "Results-Based Management" (CIDA, 2009; tinyurl.com/8xfdayn)

- "Logic Model Development Guide” (W.K. Kellogg Foundation, 2004; tinyurl.com/2bd6538)

- “Logic Model Workbook” (Innovation Network: tinyurl.com/6s5qyjh)

\section{About the Author}

Chris McPhee is Editor-in-Chief of the Technology Innovation Management Review and is in the Technology Innovation Management program at Carleton University in Ottawa. Chris received his $\mathrm{BScH}$ and MSc degrees in Biology from Queen's University in Kingston, following which he worked in a variety of management, design, and contentdevelopment roles on science-education software projects in Canada and Scotland.

Citation: McPhee, C. 2012. Results-Based Organization Design for Technology Entrepreneurs. Technology Innovation Management Review. May 2012: 10-17. (cc) BY 